\title{
ĐÁNH GIÁ CôNG TÁC QUẢN LÝ-MUA SẮM THIẾT BI VậT TƯ, HÓA CHẤT VÀ SINH PHẨM TẠI BỆNH VIỆN NGUYỄN ĐìnH CHIỂU TỈNH BẾN TRE NĂM 2020
}

\author{
Dương Thị Thanh Thảo1, Huỳnh Thị Mỹ Duyên²
}

\section{TÓM TẮT}

Đăt vấn đề: Thiết bi vật tư, hóa chất, sinh phẩm là một trong các yếu tố quan trọng trong quá trình xét nghiểm. Thực hiện tốt quản lý-mua sắm thiết bị vật tứ, hóa chất, sinh phẩm theo quy định nhằm đảm bảo kết quả xét nghiệm chính xác giúp cho việc chẩn đoán và điều trị hiệu quả. Mục tiêu nghiên cứu: (1)Xác định tỷ lệ đạt trong đánh giá các tiêu chí về xây dựng quy trinh, lưu trữ thông tin, lựa chọn mua sắm, lưu trữ bảo quản thiết bị vật tư, hóa chất và sinh phẩm; (2). Đánh giá mức chất lượng theo Quyết định 2429/QĐBYT trong công tác quản lý-mua sắm thiết bị vật tư, hóa chất và sinh phẩm tại khoa xét nghiệm của bệnh viện Nguyễn Đình Chiểu tỉnh Bến Tre năm 2020. Đối tượng và phương pháp nghiên cứu: Nghiên cứu mô tả cắt ngang hồi cứu dữ liệu có liên quan đến quản lý-mua sắm thiết bị vật tư, hóa chất, sinh phẩm sử dụng tại khoa xét nghiệm năm 2020 theo tiêu chí trong bảng kiểm Quyết định 2429, dữ liêu được phân tích trên phần mềm SPSS 20.0 Kết quả: Tỷ lệ đạt về xây dựng quy trình, lưu trữ thông tin, lựa chọn mua sắm là $83,3 \%$; tỷ lệ đạt về bảo quản thiết bị vật tư, hóa chất và sinh phẩm là $60,0 \%$; tỷ lệ số điểm khoa xét nghiệm đạt được là 84,8\%; đạt mức 3. Kết luận: viêc thực hiện quản lý-mua sắm thiết bi vật tư, hóa chất, sinh phẩm tại khoa xét nghiệm bệnh viện Nguyễn Đình Chiểu chưa đạt theo quy định của Bộ Y tế.

Tư khóa: Quyết định 2429, thiết bị vật tư, hóa chất, sinh phẩm.

\section{SUMMARY \\ AN QUALITY ASSESSMENT TO THE MANAGEMENT AND PURCHASE OF MEDICAL MATERIAL, CHEMICAL, AND BIOLOGICAL PRODUCTS AT NGUYEN DINH CHIEU HOSPITAL, BEN TRE PROVINCE, 2020 \\ Background: Medical material, chemical and biological products are major factors to testing processes. A standardized process to the management and purchase of medical material, checmical and biological products are significant to ensure accurate testing results supporting for effective diagnosis and treatment. Objectives: (1) An assessment was performed to determine the pass rate of several criteria, such as process construction, data archive, purchase selection, storage and preservation of}

${ }^{1}$ Bệnh viện Nguyễn Đình Chiểu
${ }^{2}$ Trường Đai hoc Y Dước Cần Thơ

Chịu trách nhiệm chính: Dương Thị Thanh Thảo

Email: duongthithanhthaobvndc@gmail.com

Ngày nhận bài: 29.7.2021

Ngày phản biên khoa hoc: 27.9.2021

Ngày duyệt bài: 1.10.2021 medical meterial, chemical and biological products; (2) A specific assessment of the quality level was conducted against the Decision 2429/QD-BYT for the management and purchase of medical material, chemical and biological products at the laboratory of Nguyen Dinh Chieu hospital, Ben Tre province in 2020. Research object and methodology: A crosssectional descriptive method was studied on the past data of the the management and purchase against the Decision 2429/QD-BYT at the laboratory in 2020. SPSS version 2.0 was used to analyze the data. Resuls: the pass rate of the process construction, data archive, purchase selection was $83.3 \%$; the pass rate of storage and preservation was $60.0 \%$; the pass rate of the laboratory was $84.8 \%$ and standed at level 3 . Conclutions: The management and purchase of medical material, chemical and biological products at Nguyen Dinh Chieu hospital's laboratory has not met the regulations of the Ministry of Health.

Key works: Decision 2429, medical material, chemical, biological product.

\section{I. ĐĂT VẤN ĐỀ}

Xét nghiệm là phần cận lâm sàng đặc biệt quan trọng do góp phần chẩn đoán chính xác trong quá trình điều trị. Trong quá trình xét nghiệm cần phải sử dụng các loại thiết bị vật tư, hóa chất, sinh phẩm. Việc quản lý các thiết bị vật tư, hóa chất, sinh phẩm không được kiểm soát thực hiện theo quy định để đảm bảo chất lượng thì có thể ảnh hưởng đến kết quả xét nghiệm và hiệu quả điều trị. Tại Việt Nam, công tác quản lý thiết bị vật tư, hóa chất và sinh phẩm tại phòng xét nghiệm còn hạn chế. Để quản lý tốt công tác này, Bộ Y tế ban hành một số văn bản quy định và bộ Tiêu chí đánh giá chất lượng theo Quyết định 2429/QĐ-BYT trong đó có quy định đánh giá về quản lý mua sắm thiết bị vật tư, hóa chất, sinh phẩm [1], [2], [3], [5]. Theo đó, các cơ sở y tế cần tiến hành đánh giá mức chất lượng đạt được để báo cáo về cơ quan quản lý và khắc phục các điểm còn tồn tại. Hiện nay, tại bệnh viện Nguyễn Đình Chiểu, công tác quản lý thiết bị vật tư, hóa chất, sinh phẩm xét nghiệm tại khoa Xét nghiệm chưa đạt theo quy định. Để có cơ sở trong việc tiếp tục cải tiến chất lượng, đề tài "Đánh giá công tác quản lý - mua sắm thiết bị vật tư, hóa chất và sinh phẩm tại bệnh viện Nguyễn Đình Chiểu tỉnh Bến Tre năm 2020" thực hiện với mục tiêu:

1. Xác định tỷ lệ đạt trong đánh giá các tiêu 
chí về xây dựng quy trinh, lưu trữ thông tin, lựa chon mua sắm; lưu trữ, bảo quản thiêt bị vật tư, hóa chất và sinh phẩm theo Quyêt định 2429/QD-BYT tại khoa Xét nghiệm bệnh viện Nguyển Đinh Chiểu tỉnh Bến Tre năm 2020.

2. Đánh giá mức chât lượng theo Quyêt định 2429/QD-BYT trong công tác quản lý-mua sắm thiêt bị vật tư, hóa chât và sinh phẩm tại khoa Xét nghiệm của bệnh viện Nguyễn Đinh Chiêu tỉnh Bến Tre năm 2020.

\section{II. ĐỐI TƯƠNGG VÀ PHƯƠNG PHÁP NGHIÊN CỨU}

2.1. Đối tượng nghiên cứu. Các báo cáo, hồ sơ của hóa chất, vật tư, sinh phẩm có liên quan đến công tác quản lý - mua sắm thiết bị vật tư, hóa chất và sinh phẩm theo Quyết định 2429/QĐ-BYT tại khoa Xét nghiệm của bệnh viện Nguyễn Đình Chiểu.

Tiêu chuẩn chọn mẫu: Tất cả các số liệu báo cáo, hồ sơ liên quan đến các tiêu chí trong bảng kiểm theo Quyết định 2429/QĐ-BYT.

Tiêu chuẩn loại trừ: các báo cáo, hồ sơ không liên quan đến tiêu chí trong bảng kiểm.

\subsection{Phương pháp nghiên cứu}

Thiết kế nghiên cứu: Nghiên cứu mô tả cắt ngang dưa trên dữ liệu hồi cứu.

Cỡ mẫu và phương pháp chon mẫu: Tất cả các hóa chất, vật tư, sinh phẩm (tổng cộng gồm 182 loại) được sử dụng tại khoa Xét nghiệm của bệnh viện Nguyễn Đinh Chiểu và các số liệu về báo cáo, hồ sơ của các hóa chất, vật tư, sinh phẩm này có liên quan đến các tiêu chí trong bảng kiểm. Biến số nghiên cứu: hồ sơ thông tin, quy trình, bảo quản các thiết bị vật tư vật tư, hóa chất, sinh phẩm có liên quan đến tiêu chí chất lượng từ 7.1 đến 7.17 của Quyết định 2429/QĐ-BYT.

Phương pháp đánh giá: Theo Quyết định 2429/BYT-Đánh giá là "đạt" khi có đủ các yêu cầu theo quy định, đánh giá là "đạt một phần" khi đạt được ít nhất 50\% các yêu cầu theo quy định, đánh giá là "không đạt" khi đạt dưới 50\% các yêu câuu theo quy định. Điểm đánh giá tổng hợp các tiêu chí theo Quyết định 2429/QĐ-BYT được tính toán dựa trên điểm tối đa như sau: khi tiêu chí được đánh giá là "đạt" thì điểm đánh giá bằng điểm tối đa; khi đánh giá là "đạt một phần" thì nhận được $1 \frac{1}{2}$ số điểm của điểm tối đa; khi đánh giá là "không đạt" thì số điểm đánh giá là 0 ; khi đánh giá là "không áp dụng" thì số điểm đánh giá bằng điểm tối đa đối với trường hợp không bắt buộc thực hiện theo quy định, số điểm đánh giá bằng 0 đối với trường hợp bắt buộc thực hiện theo quy định. Đánh dấu $X$ vào phương án trả lời cho mỗi tiêu chí và ghi điểm vào cột "Điểm đánh giá". Đánh giá mức chất lượng được căn cứ vào số điểm và tỷ lệ \% so với điểm tối đa phòng xét nghiệm đạt được sau khi đánh giá, gồm các mức như sau: chưa xếp mức (dưới 20\% điểm tối đa), mức $1(20 \%-<35 \%$ điểm tối đa), mức 2 (35\% - <65\% điểm tối đa), mức 3 (65\% - <85\% điểm tối đa), mức 4 (85\% $<95 \%$ điểm tối đa), mức 5 ( $\geq 95 \%$ điểm tối đa).

Phương pháp thu thập số liệu: Tiến hành thu thập số liệu trên toàn bộ mấu nghiên cứu theo các tiêu chí trong bảng kiểm.

Phương pháp xử lý số liệu: Xử lý số liệu bằng phần mềm SPSS 20.

\section{KẾT QUẢ NGHIÊN CỨU}

3.1. Tỷ lệ đạt trong đánh giá các tiêu chí về xây dựng quy trình, lưu trữ thông tin, lựa chọn mua sắm; lưu trữ, bảo quản thiết bị vật tư, hóa chất và sinh phẩm theo Quyểt định 2429/QĐ-BYT tại khoa Xét nghiệm năm 2020

3.1.1. Tỷ lệ đạt trong đánh giá các tiêu chí về việc xây dựng quy trinh, lưu trữ thông tin, lưa chọn mua săm

Bảng 3.1. Tỷ lệ đạt trong đánh giá các tiêu chí về việc xây dựng quy trinh và lưu trữ thông tin, lựa chọn mua sắm

\begin{tabular}{|c|c|c|c|c|c|c|c|c|c|}
\hline \multirow{3}{*}{$\begin{array}{l}\text { Tiêu } \\
\text { chí }\end{array}$} & \multirow{3}{*}{ Nội dung đánh giá } & \multicolumn{8}{|c|}{ Số lượng (n = 182) } \\
\hline & & \multicolumn{2}{|c|}{ Đạt } & \multicolumn{2}{|c|}{$\begin{array}{l}\text { Đạt một } \\
\text { phân }\end{array}$} & \multicolumn{2}{|c|}{$\begin{array}{c}\text { Không áp } \\
\text { dụng }\end{array}$} & \multicolumn{2}{|c|}{$\begin{array}{l}\text { Không } \\
\text { đạt }\end{array}$} \\
\hline & & n & $\%$ & $\mathbf{n}$ & $\%$ & $\mathbf{n}$ & $\%$ & $\mathbf{n}$ & $\%$ \\
\hline 7.1 & Quy trình mua sắm (có xây dựng SOP) & 182 & 100,0 & 0 & 0 & 0 & 0 & 0 & 0 \\
\hline 7. & $\begin{array}{l}\text { Kế hoạch mua sắm (dự trù) được trưởng } \\
\text { khoa xác nhận }\end{array}$ & 182 & 100,0 & 0 & 0 & 0 & 0 & 0 & 0 \\
\hline 7.3 & $\begin{array}{l}\text { Có tham gia vào quá trình xây dựng nhu } \\
\text { câu, lựa chọn nhà thầu (xem hồ sơ lưu) }\end{array}$ & 182 & 100,0 & 0 & 0 & 0 & 0 & 0 & 0 \\
\hline 7.4 & $\begin{array}{l}\text { Có cập nhật danh sách các nhà cung ứng đã } \\
\text { được duyệt (tên công ty, địa chỉ, số điện thoại) }\end{array}$ & 147 & 80,8 & 35 & 19,2 & 0 & 0 & 0 & 0 \\
\hline 7.5 & $\begin{array}{l}\text { Có đánh giá chất lượng của các nhà cung } \\
\text { ứng (trong biên bản họp với lãnh đạo) }\end{array}$ & 182 & 100,0 & 0 & 0 & 0 & 0 & 0 & 0 \\
\hline
\end{tabular}


VIETNAM MEDICAL JOURNAL N²2 - OCTOBER - 2021

\begin{tabular}{|c|c|c|c|c|c|c|c|c|c|}
\hline \begin{tabular}{|l|}
7.6 \\
7.12 \\
\end{tabular} & $\begin{array}{c}\text { Quy trình tiếp nhận, tài liệu hướng dấn } \\
\text { sứ dụng }\end{array}$ & 182 & 100,0 & 0 & 0 & 0 & 0 & 0 & 0 \\
\hline 7.9 & $\begin{array}{l}\text { Đánh giá chất lượng (các giấy xác nhận } \\
\text { chất lượng của nhà sản suất) }\end{array}$ & 182 & 100,0 & 0 & 0 & 0 & 0 & 0 & 0 \\
\hline 7.14 & $\begin{array}{l}\text { Hồ sơ lưu các thông tin khi tiếp nhâan sử } \\
\text { dụng: số lô, số lượng, ngày nhận, tình trạng } \\
\text { khi nhận; ngày mở, ngày hết hạn }\end{array}$ & 103 & 56,6 & 79 & 43,4 & 0 & 0 & 0 & 0 \\
\hline 7.16 & $\begin{array}{l}\text { Quy trình, hồ sơ xử lý hóa chất, vật tư, sinh } \\
\text { phẩm hết hạn hoặc không đạt chuẩn }\end{array}$ & 182 & 100,0 & 0 & 0 & 0 & 0 & 0 & 0 \\
\hline 7.15 & $\begin{array}{l}\text { Lưu trữ hồ sơ hóa chất, sinh phẩm/môi } \\
\text { trường do phòng xét nghiệm tự chuẩn bị }\end{array}$ & 0 & 0 & 0 & 0 & 182 & $\begin{array}{c}100 \\
0\end{array}$ & 0 & 0 \\
\hline 7.17 & $\begin{array}{c}\text { Kế hoạch, quy trình xữ lý, hồ sơ liên quan } \\
\text { việc gián đoạn dịch vụ xét nghiệm }\end{array}$ & 182 & 100,0 & 0 & 0 & 0 & 0 & 0 & 0 \\
\hline
\end{tabular}

Nhân xét: Số lượng tiêu chí đat tỷ lệ $100 \%$ các nôii dung theo quy định về xây dựng quy trình, lưu trữ hồ sơ, lựa chọn mua sắm gồm 10/12 tiêu chí chiếm tỷ lệ 83,3\%.

3.1.2. Tý lể đạt trong đánh giá các tiêu chí về đánh giá việc thực hiện lưu trữ, bảo quản vật tư, hóa chất, sinh phẩm

Bảng 3.2. Tỷ lệ đạt trong đánh giá các tiêu chí về đánh giá việc thực hiện lưu trữ, bảo quản vật tư, hóa chất, sinh phẩm

\begin{tabular}{|c|c|c|c|c|c|c|c|c|c|}
\hline \multirow{3}{*}{$\begin{array}{l}\text { Tiêu } \\
\text { chí }\end{array}$} & \multirow{3}{*}{ Nội dung đánh giá } & \multicolumn{8}{|c|}{ Số lượng (n = 182) } \\
\hline & & \multicolumn{2}{|c|}{ Đạt } & \multicolumn{2}{|c|}{$\begin{array}{l}\text { Đạt một } \\
\text { phân }\end{array}$} & \multicolumn{2}{|c|}{$\begin{array}{l}\text { Không áp } \\
\text { dụng }\end{array}$} & \multicolumn{2}{|c|}{$\begin{array}{l}\text { Không } \\
\text { đạt }\end{array}$} \\
\hline & & $\mathbf{n}$ & $\%$ & $\mathbf{n}$ & $\%$ & $\mathbf{n}$ & $\%$ & $\mathbf{n}$ & $\%$ \\
\hline $\begin{array}{l}7.7 \\
7.11\end{array}$ & $\begin{array}{l}\text { Khu vực bảo quản lưu trữ theo } \\
\text { quy định }\end{array}$ & 182 & 100,0 & 0 & 0 & 0 & 0 & 0 & 0 \\
\hline 7.8 & $\begin{array}{c}\text { Không thực hiện lưu trữ hóa chất, } \\
\text { vật tư, sinh phẩm }\end{array}$ & 0 & 0 & 0 & 0 & 182 & 100,0 & 0 & 0 \\
\hline 7.10 & $\begin{array}{l}\text { Các hóa chất, sinh phẩm, vật tư } \\
\text { hết hạn được lưu trữ riêng và dán } \\
\text { nhãn cảnh báo }\end{array}$ & 0 & 0 & 0 & 0 & 0 & 0 & 06 & 3,3 \\
\hline 7.13 & $\begin{array}{l}\text { Kiểm tra việc sắp xếp, lưu trữ hóa } \\
\text { chất, vật tư, sinh phẩm theo FIFO }\end{array}$ & 151 & 83,0 & 0 & 0 & 0 & 0 & 31 & 17,0 \\
\hline
\end{tabular}

Nhân xét: số lượng tiêu chí đạt tỷ lệ $100 \%$ các nội dung về lưu trữ, bảo quản theo quy định gồm $3 / 5$ tiêu chí chiếm tỷ lệ 60,0\%.

Như vậy, tỷ lê đạt trong đánh giá các tiêu chí về xây dựng quy trình, lưu trữ thông tin, lựa chọn mua sắm; lưu trữ, bảo quản thiết bị vật tư, hóa chất và sinh phẩm theo Quyết định 2429/QĐ-BYT với tổng các tiêu chí đạt được 100\% các nội dung theo quy định của Quyết định 2429 trong công tác quản lý - mua sắm thiết bị vât tư, hóa chất, sinh phẩm gồm 13/17 tiêu chí chiếm tỷ lệ là 76,5\%.

3.2. Đánh giá mức chất lượng theo Quyết định 2429/QĐ-BYT trong công tác quản lýmua sắm thiết bị vật tư, hóa chất và sinh phẩm tại khoa Xét nghiệm năm 2020

Bảng 3.3. Tông hợp việc đánh giá điểm thực hiện các tiêu chí theo Quyết định 2429

\begin{tabular}{|c|c|c|c|c|c|c|}
\hline Nội dung tiêu chí & Đạt & $\begin{array}{l}\text { Đạt } \\
\text { mốt } \\
\text { phần }\end{array}$ & $\begin{array}{c}\text { Không } \\
\text { đạt }\end{array}$ & $\begin{array}{c}\text { Không } \\
\text { áp } \\
\text { dung }\end{array}$ & $\begin{array}{c}\text { Điểm } \\
\text { tối đa }\end{array}$ & $\begin{array}{c}\text { Điểm } \\
\text { đánh giá }\end{array}$ \\
\hline 7.1. Có quy trình lựa chọn mua sắm & $\mathrm{X}$ & & & & 1 & 1 \\
\hline 7.2. Có kế hoạch nhu cầu TTB, vật tứ, hóa chất và sinh phấm & $\mathrm{X}$ & & & & 1 & 1 \\
\hline $\begin{array}{l}\text { 7.3. Có tham gia vào quá trình xây dựng nhu cầu, lựa } \\
\text { chọn nhà thâuu }\end{array}$ & $\mathrm{X}$ & & & & 2 & 2 \\
\hline $\begin{array}{l}\text { 7.4. Có cập nhật danh sách các nhà cung ứng hóa chất } \\
\text { và sinh phẩm }\end{array}$ & & $\mathrm{X}$ & & & 1 & 0,5 \\
\hline 7.5. Có đánh giá chất lượng của nhà cung ứng & $\mathrm{X}$ & & & & 1 & $\mathbf{1}$ \\
\hline 7.6. Có quy trình tiếp nhận, bảo quản & $\mathrm{X}$ & & & & 1 & \\
\hline 7.7. Khu vực lưu trữ, bảo quản hóa chất có đủ không & $\mathrm{X}$ & & & & 2 & 2 \\
\hline
\end{tabular}




\begin{tabular}{|c|c|c|c|c|c|c|}
\hline gian và sắp xếp đảm bảo yêu cầu & & & & & & \\
\hline $\begin{array}{l}\text { 7.8. Nếu không thực hiện lưu trữ tại khoa xét nghiệm, } \\
\text { thì có kiểm tra khổng gian và điều kiện nơi bảo quản }\end{array}$ & & & & $\mathrm{X}$ & 1 & 1 \\
\hline $\begin{array}{c}\text { 7.9. Đối với mô̂i kít xét nghiệm hoặc lô hóa chất mới } \\
\text { nhận có giấy xác nhâân chất lượng của nhà sản xuất } \\
\text { trước khi tiếp nhận sữ dụng } \\
\end{array}$ & $\mathrm{X}$ & & & & 1 & 1 \\
\hline $\begin{array}{l}\text { 7.10. Các hóa chất hết hạn hoă̆c không đạt chất lượng } \\
\text { được dán nhã̃n và lưu trữ riêng }\end{array}$ & & & $\mathrm{X}$ & & 1 & $\mathbf{0}$ \\
\hline 7.11. Hóa chất, sinh phấm độc hại được lưu trữ đúng quy định & $\mathrm{X}$ & & & & 1 & $\mathbf{1}$ \\
\hline 7.12. Có hướng dấn sử dụng hóa chất, sinh phẩm, vật tư & $\mathrm{X}$ & & & & 1 & $\mathbf{1}$ \\
\hline 7.13. Có thực hiện Quy tắc FEFO & & $\mathrm{X}$ & & & 1 & 0,5 \\
\hline $\begin{array}{c}\text { 7.14. Có lưu các hồ sơ liên quan đến hóa chất xét } \\
\text { nghiệm khi tiếp nhạạn }\end{array}$ & & $\mathrm{X}$ & & & 3 & 1,5 \\
\hline $\begin{array}{l}\text { 7.15. Với những hóa chất, sinh phẩm/môi trường tự } \\
\text { chuẩn bị, tự pha chế thì có lưu trữ thông tin người } \\
\text { chuẩn bị, hạn sữ dụng (nếu có) }\end{array}$ & & & & $\mathrm{x}$ & 1 & 1 \\
\hline $\begin{array}{l}\text { 7.16. Xử lý đúng quy định các hóa chất hết hạn hoặc } \\
\text { không đạt tiêu chuẩn }\end{array}$ & $\mathrm{X}$ & & & & 1 & 1 \\
\hline $\begin{array}{l}\text { 7.17. PXN không bị gián đoạn dịch vụ XN do nguyên } \\
\text { nhân liên quan đến hóa chất, vật tư, sinh phẩm }\end{array}$ & $x$ & & & & 3 & 3 \\
\hline Tổng điểm & & & & & 23 & 19,5 \\
\hline
\end{tabular}

Nhân xét: Tống điểm đạt được trong đánh giá thực hiện các tiêu chí là 19,5/23 điếm. Trong quản lý thiết bị vật tư, hóa chất, sinh phẩm khoa xét nghiệm đạt được 19,5 điểm chiếm tỷ lệ 84,8 \% so với điểm tối đa, đạt mức 3 theo quy định.

\section{BÀN LUÂ̂N}

4.1. Tỷ lệ đạt trong đánh giá các tiêu chí về xây dựng quy trình, lưu trữ thông tin, lựa chọn mua sắm; lưu trữ bảo quản thiết bị vật tư, hóa chất và sinh phẩm theo Quyểt định 2429/QĐ-BYT tại khoa Xét nghiệm năm 2020

4.1.1. Tỷ lệ đạt trong đánh giá các tiêu chí về việc xây dựng quy trinh, lưu trữ thông tin, lựa chọn mua sắm. Qua nghiên cứu, số lượng tiêu chí đạt tỷ lệ $100 \%$ các nội dung theo quy định về xây dựng quy trình, lưu trữ hồ sơ, lựa chọn mua sắm gồm 10/12 tiêu chí chiếm tỷ lệ $83,3 \%$. Trong đó, khoa xét nghiệm có xây dựng đầy đủ các quy trình về mua sắm, tiếp nhận lưu trữ, bảo quản, quy trình xử lý hóa chất, vật tư, sinh phẩm hết hạn hoặc không đạt chuẩn, kế hoạch mua sắm (dự trù) được thực hiện theo quy định của Quyết định 2429/QĐ-BYTT [1]. Kết quả này phù hợp với nghiên cứu của Nguyễn Thị Nhung năm 2017 tại bệnh viện 19 8, Bộ Công an [6]. Về lưu trữ thông tin trong hồ sơ mua sẳm trong việc cập nhật danh sách các nhà cung ứng thiết bị vật tư, hóa chất và sinh phẩm đã được duyệt (tển công ty, địa chỉ, số điện thoại): có lưu trữ đầy đủ chiếm tỷ lệ $80,8 \%$, chưa lưu trữ đầy đủ thông tin theo quy định chiếm tỷ lệ $19,2 \%$. Kết quả này thấp hơn quy định [1]. Ở tiêu chí 7.14: khoa Xét nghiệm ghi chép chưa đầy đủ các nội dung: số lô, ngày mở, ngày hết hạn của hóa chất, sinh phẩm sau khi tiếp nhận sử dụng chiếm tỳ lệ $43,4 \%$. Theo quy định, sau khi mở nắp lọ hóa chất, phần còn lại sẽ được bảo quản theo tờ hướng dấn sử dung, nhà sản xuất sẽ ghi hạn dùng sau khi mở nắp, ngày hết hạn. Nếu quá thời hạn quy định sau khi mở nắp theo hướng dẫn của nhà sản xuất thì hóa chất, sinh phẩm sẽ không đảm bảo chất lượng. Qua khảo sát, tỷ lệ thực hiện ghi chép đầy đủ các thông tin về số lố, ngày nhận, ngày mở, ngày hết hạn của vật tư, hóa chất, sinh phẩm là $56,6 \%$ thấp hơn so với quy định của Quyết định 2429/QĐ-BYT[1]. Về đánh giá tiêu chí 7.15: hiện tai, tất cả các hóa chất, sinh phẩm/môi trường đều được mua từ kết quả trúng thầu của bênh viện. Các sản phẩm trúng thầu này đạt tiêu chuẩn chất lượng và được Bộ $Y$ tế cấp số đăng ký lưu hành với giá cả phù hợp cho việc thực hiện kỹ thuật xét nghiệm tại bệnh viện. Trong khi đó, nếu khoa Xét nghiệm tự pha chế thì gặp nhiều khó khăn như khó tìm nguyên liệu, khó tìm nơi để kiểm nghiệm chất lượng theo quy định; bên cạnh đó chi phí để có được một sản phẩm đạt tiểu chuẩn chất lượng theo quy định sẽ cao hởn sản phẩm bệnh viện mua từ kết quả trúng thầu. Vì vậy, khoa Xét nghiệm không tự chuẩn bị cũng như không tự pha chế các hóa chất, sinh phẩm/môi trường. Theo Quyết định 2429, ở tiêu 
chí 7.15 không bắt buộc phòng xét nghiệm phải thực hiện việc tự pha chế nên khoa Xét nghiệm không áp dụng tiêu chí này [1].

4.1.2. Tỷ lê đạt trong đánh giá các tiêu chí về đánh giá việc thực hiện lưu trữ, bảo quản vật tư, hóa chất, sinh phẩm. Qua nghiên cứu, số lượng tiêu chí đạt tỷ lệ 100\% các nội dung về lưu trữ, bảo quản theo quy định gồm $3 / 5$ tiêu chí chiếm tỷ lệ $60,0 \%$. Trong đó, đánh giá về điều kiện bảo quản: khu vực bảo quản được thực hiện theo quy định. Kết quả này phù hợp với nghiên cứu của Nguyễn Thị Nhung năm 2017 tại bệnh viện 19 - 8, Bộ Công an [6]. Ở tiêu chí 7.8: theo tiêu chuẩn ngành, khoa xét nghiệm phải đảm bảo đủ các phòng cần thiết cho hoạt động chuyên môn bao gồm kho (để lưu trữ vật tư, hóa chất, sinh phẩm...) [4]. Vì vậy, khoa Xét nghiệm không áp dụng tiêu chí 7.8 (quy định về không thực hiện lưu trữ hóa chất, sinh phẩm, vật tư tại khoa xét nghiệm) [1]. Đánh giá việc sắp xếp, lưu trữ hóa chất, vật tư, sinh phẩm theo FIFO: thực hiện các biện pháp như sắp xếp và cấp sử dụng theo nguyên tắc FIFO, báo cáo hàng tháng hóa chất có hạn sử dụng ngắn, dán nhãn trên kệ để cảnh báo là một trong những biện pháp có thể quản lý hạn sử dụng. Việc sắp xếp theo FIFO và kiểm soát hạn sử dụng nhằm phát hiện kịp thời hóa chất hết hạn sử dụng và đưa vào khu vực biệt trữ để tránh việc sứ dụng hóa chất hết hạn, không đảm bảo chất lượng xét nghiệm. Ở tiểu chí 7.10 và 7.13 khoa Xét nghiệm thực hiện không đạt theo bảng kiểm của Quyết định 2429/QĐ-BYT [1], việc sắp xếp đạt theo FIFO chiếm tỷ lệ $83 \%$ (151/182), việc kiểm soát hạn dùng cho thây chỉ $83 \%$ sắp xếp và cấp phát sử dụng theo nguyên tắc FIFO, không theo dõi hạn dùng của hóa chất cũng như các hóa chất gần hết hạn sử dụng không được dán nhãn cảnh báo chiếm tỳ lệ $17 \%$. Trong đó có 06 loại hóa chất hết hạn sử dụng chưa để ở khu vực riêng và dán nhãn cảnh báo chiếm tỷ lệ 3,3\%; nếu sơ suất lấy nhầm các hóa chất hết hạn này để sử dụng thì sẽ làm ảnh hưởng đến kết quả xét nghiệm có thể gây hậu quả nghiêm trọng đến việc chẩn đoán và điêu trị.

4.2. Đánh giá mức chất lượng theo Quyết định 2429/QĐ-BYT trong công tác quản lý-mua sắm thiết bị vật tứ, hóa chất và sinh phẩm tại khoa Xét nghiệm năm 2020. Qua nghiên cứu, việc quản lý - mua sắm thiết bị vật tư, hóa chất, sinh phẩm đạt với với số điểm đánh giá là 19,5/23 điểm, chiếm tỷ lê 84,8\%. Trong đó, các tiêu chí đạt được điểm tối đa gồm $13 / 17$ tiêu chí chiếm tỷ lệ $76,5 \%$, các tiêu chí đạt một phần gồm 03 tiêu chí (chiếm tỷ lệ 17,6\%), tiêu chí không đạt gồm 01 tiêu chí (chiếm tỷ lệ 5,9\%), các tỷ lệ đạt còn thấp hơn so với quy định [1]. Trong 04 tiêu chí chưa đạt điểm tối đa có 02/04 tiêu chí chưa đạt về lưu trữ, bảo quản hóa chất, sinh phẩm liên quan đến việc sắp xếp theo quy định, nếu không tuân thủ theo quy định này thì sẽ khó khăn cho việc kiểm soát hạn dùng, dế xảy ra sai sót trong quá trình cấp phát sử dụng, nghiêm trọng là cấp nhầm hóa chất hết hạn sử dụng có thể ảnh hưởng đến kết quả xét nghiệm.

Theo quy định về mức chất lượng của Quyết định 2429/QĐ-BYT: đánh giá mức chất lượng được căn cứ vào số điểm và tỷ lệ \% so với điểm tối đa phòng xét nghiệm đạt được sau khi đánh giá, đạt mức 3 có tỷ lệ số điểm đánh giá từ $65 \%$ - <85\% điểm tối đa. Qua nghiên cứu, khoa Xét nghiệm đạt được tỷ lệ 84,8\% so với điểm tối đa, đạt được mức 3 theo quy định [1]. Để nâng chất lượng phòng xét nghiệm tiến tới tiêu chuẩn ISO 15189, khoa Xét nghiệm cần khắc phục các tiêu chí chưa đạt về lưu trữ hồ sơ, bảo quản thiết bị vật tư, hóa chất, sinh phẩm trong công tác quản lý-mua sắm thiết bị vật tư, hóa chất, sinh phẩm.

\section{KẾT LUÂN}

Tỷ lệ tiêu chí khoa Xét nghiệm thực hiện đạt được là $84,8 \%$, đạt mức 3 . Kết quả nghiên cứu có thể giúp khoa xét nghiệm đề ra giải pháp khắc phục các tiêu chí chưa đạt trong kiểm tra, giám sát việc thực hiện theo quy định của Bộ Y tế.

\section{TÀI LIÊU THAM KHẢO}

1. Bộ Y tế (2017), Quyết định 2429/QĐ-BYT ngày 12 tháng 6 năm 2017, ban hành Tiêu chí đánh giá mức chất lượng phòng xét nghiệm y học.

2. Bố Y tế (2016), Quyết đinh $6858 / Q \dot{Đ}-B Y T$ ngày 18 tháng 11 năm 2016, ban hành Bộ tiêu chí chât lượng bệnh viện Việt Nam.

3. Bồ Y tế (2013), Thông tư số 01/2013/TT-BYT ngày 11 tháng 01 năm 2013, hướng dânn đảm bảo chất lượng xét nghiệm đối với các cơ sở khám chữa bệnh.

4. Bô̂ Y tể (2005), Quyết định 35/QĐ-BYT ngày 31 tháng 5 năm 2005, ban hành tiêu chuẩn thiêt kế khoa xét nghiệm bệnh viện đa khoa-Tiêu chuẩn ngành

5. Thủ tướng chính phủ (2016), Quyết đinh số $316 / Q Đ-T T$ g ngày 27 tháng 02 năm 2016 về Phê duyệt Đề án tăng cường năng lực hệ thống quản lý chất lượng xét nghiệm y học giai đoạn 2016 - 2025.

6. Nguyển Thị Nhung (2017), Thực trạng công tác quản lý chất lượng xét nghiệm tại khoa hóa sinh bệnh viện 19-8 Bộ Công an năm 2017, Luận văn thạc sĩ, Quản lý bệnh viện, Trường Đại học Y tế công cộng. 